\title{
ISLAMIC URBAN HERITAGE: BLIGHT OR BLESSING?
}

\author{
D. BOUSSAA \\ Department of Architecture and Urban Planning, College of Engineering, Qatar University, Qatar.
}

\begin{abstract}
After gaining independence in the 1950s and 1960s, many countries in the Arab world witnessed a staggering rapid urban growth. The Islamic urban centres, which formed the central parts of these cities, witnessed continuous pressures of redevelopment and destruction. A large number of these centres with rich urban and architectural values were often demolished and replaced by high-rise buildings. Following the period of development and rapid urbanization, people started to realize that their cities have lost their identity and character in the mainstream of the globalization trends. The historic centres and urban cores, which escaped complete demolition, have survived as isolated pockets in the middle of hybrid environments. This dilemma raises important questions: is this surviving Islamic urban heritage blight or blessing? Is it 'blight' and obstacle that prevents the present cities from growing and prospering, or is it an asset that can form a major catalyst to promote these cities while maintaining strong roots with their past? Therefore, what will be the future of our Islamic urban centres? Will they be demolished to pave way for more ambitious growth or will they be conserved and sustained for present and future generations? Will the historic city, the heart of urban life and the main protector of the present cities' identities, survive and continue to be places for living within the emerging global environments of today and tomorrow? Despite the globalization trends that are wiping local cultures and traditions, it is possible to counterbalance this drift by preserving the few remaining patches of these historic cities. This article believes that one way of developing the present Arab city is to look at this urban heritage as 'blessing' and try to conserve it. In this context, this article discusses the following question: How can Islamic urban heritage be a setting of an appropriate urban regeneration of the Arab city today and in the future? In order to discuss this issue, examples of the Casbah of Algiers in Algeria and the Medina of Tunis in Tunisia are presented. Keywords: development, globalization, identity, Islamic, urban heritage, urban regeneration.
\end{abstract}

\section{INTRODUCTION}

In the late 1950s, when most of the Arab countries gained independence, the initial goal of many governments was to erase images of under-development and poverty. To do this, they embarked on large-scale re-development projects to catch up with the modernized world, and historic centres, which were located in the heart of major cities and capitals, were seen as 'blight' and obstacle in the face of a bright future. In many parts of the Arab world entire residential areas were erased, such as the Lalahoum district in the Casbah of Algiers which was completely razed in the 1980s.

Most historic centres that escaped from destruction experienced problems in making the necessary adaptation to the present. They have suffered from neglect, lack of maintenance and deterioration. Economic decline and the original inhabitants' exodus from the historic centres led to further destruction and dilapidation. Moreover, lack of appropriate city planning and changes in consumer tastes have worsened the situation to the level of transforming these historic centres into 'slums' (UNESCO [1]).

Centrally located, these historic centres used to keep the city alive and participated in its economic growth. Today, it is rarely the case; many of these old cores have been marginalized

This paper is part of the Proceedings of the International Conference on Islamic Heritage Architecture and Art (Islamic Heritage Architecture 2016)

www.witconferences.com 
and left to face their own fate of neglect and disrepair. With land values rising, the owners of these historic centres were pressurized by land developers to tear them off for massive redevelopment projects, which would bring more financial revenues.

The viability of a historic centre depends on how its position, function and values can be sustained within the emerging global environments, particularly with respect to modern districts. Central cores were attractive because they provided a diversity of services within a small area, and within easy reach by pedestrians. The main argument of this article is to see whether there is a way to consider both the cultural and economic functions of the remaining historic centres in the Islamic world such as the Casbah of Algiers in Algeria and the Medina of Tunis in Tunisia.

\section{THE CASBAH OF ALGIERS, ALGERIA}

The Casbah of Algiers, a landmark of Algerian history in the heart of the capital city, presents a critical case for urban conservation. The United Nations Educational, Scientific and Cultural Organization (UNESCO) inscribed the Casbah of Algiers on the world heritage list in 1992, but since then there has been continuous degradation in this historic centre. This case study highlights the different ways in which the Casbah has been viewed as 'blight' since the independence of Algeria in 1962.

Algiers has an area of $276 \mathrm{~km}^{2}$ and a population of more than 3 million. The Casbah is situated on the coast to the north of the city; the complex labyrinth of streets and passages and a fortress from the 15th century remain as reminders of the past. The Casbah of Algiers was founded in the 6th century BC and was constructed on a steep slope (118 $\mathrm{m}$ high) facing the harbour bay and the Mediterranean Sea. Its original function was for military and trade.

The Casbah is characterized by a tight network of narrow streets and lanes, cut with stairs laid out on the sloped site. Occasionally, it opened up into small urban squares, usually equipped with fountains for use by neighbours and passers-by. The two main defence elements of the site were the citadel on the highest point of the hill and the harbour, which fixed the lower limits of the town with its bastions. In cosmopolitan Casbah, the principles of Turkish military architecture were combined with Moorish and Arab-Mediterranean architectural traditions. The white houses with their flat terraced roofs formed a tight and tangled ensemble that climbed the slope. In addition to housing, there were monuments, many of which were decorated with sculpted woodwork and earthen work containing gardens and fountains. These monuments, such as the mosques of Djemaa El Kebir (11th-14th centuries), Sidi Abd-Al-Rahman (18th century) and Ketchaoua (18th-19th centuries, Fig. 1), still stand out as landmarks in the landscape.

The population of the Casbah grew from 60,000 in 1969 to 70,000 in 1980. While the number of houses was reducing, the density was rising and reached 4,000 persons/ha in a few districts, making it one of the highest densities in the world (Lesbet [2]). In addition to high density and overpopulation, lack of services and poor sanitation accelerated the dereliction of the Casbah. Most of its inhabitants were waiting for an opportunity to move to a new flat. Furthermore, low rents discouraged the homeowners from investing in the maintenance of their houses, leading to more dilapidation. Because of the continuing collapse of the few remaining historic buildings, the Casbah no longer forms a compact mass. This has accentuated the decline of the area as a whole, making it an urban slum.

Despite the continuing cycle of changes and deterioration, the Casbah of Algiers still maintains its privileged place in Algerian culture and memory. The Casbah still contains houses, mosques, schools, shops, workshops, public baths, hotels and dormitories. Only about $15 \%$ of the houses are owner-occupied; mostly low-income tenants (Loeckx [3]) inhabit the rest. However, for the past 50 years, the authorities have been looking at the Casbah as a 'blight', which is disappearing day after day under the eyes of its inhabitants and the larger community in Algiers (Fig. 2). 


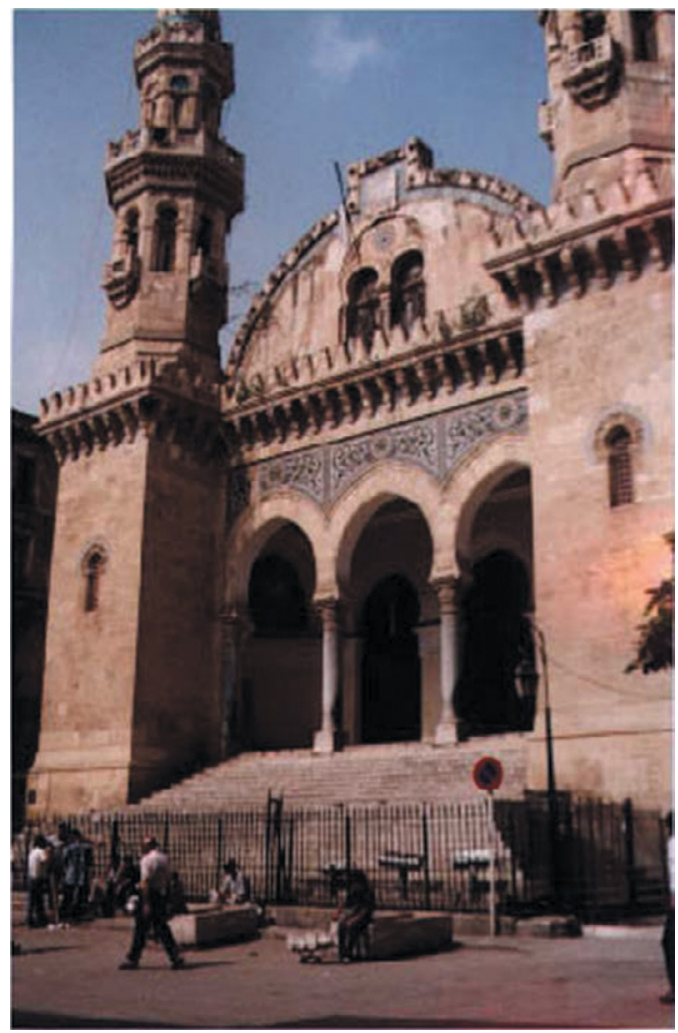

Figure 1: One of the surviving monuments, Ketchaoua mosque.

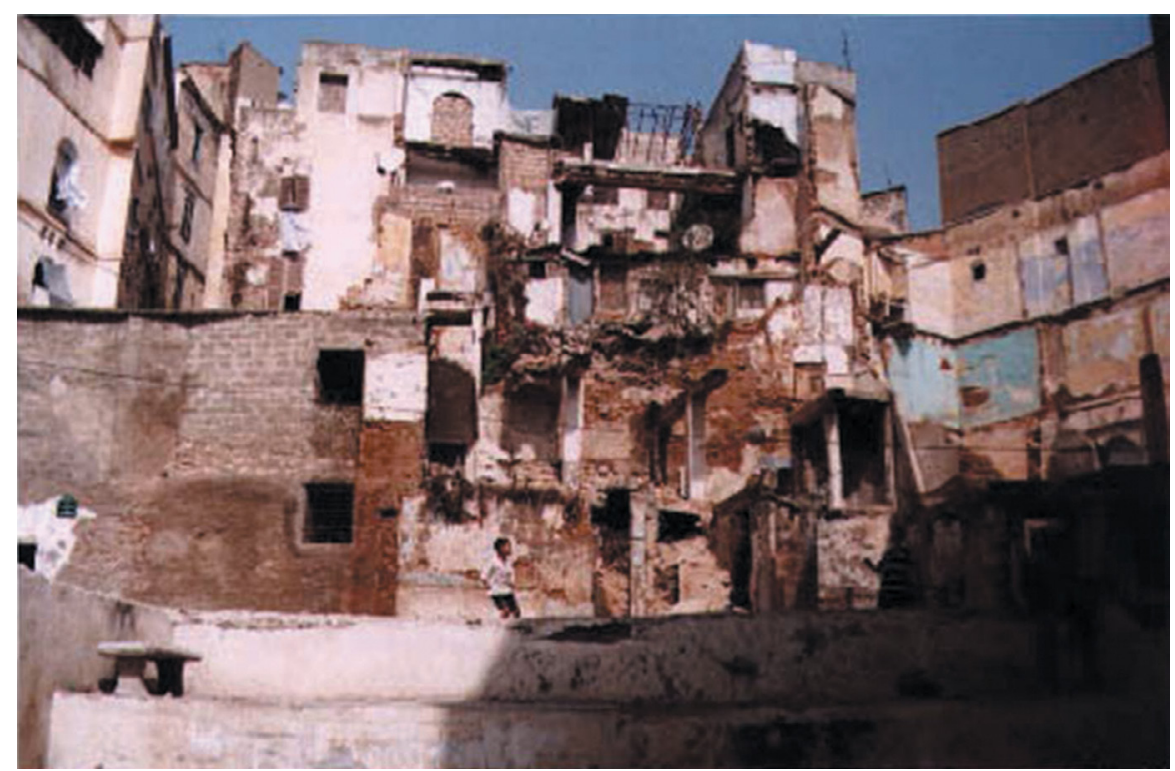

Figure 2: Advanced state of decay of the Casbah dwellings led to their continuous disrepair, deterioration and collapse. 


\subsection{The Casbah of Algiers, as blight}

The citadel was the first restoration project undertaken in the Casbah. This heritage complex encompassed the Dey Castle, the Beys castle, two mosques, gardens and annexes lying over an area of 11,000 $\mathrm{m}^{2}$. The National Agency of Archaeology and Protection of Sites and Historic Monuments (ANAPSMH) has been in charge of this project. Restoration of the historical monument (Bastion 23) was the second major action in the Casbah. This historic monument is an ensemble composed of three palaces, nine houses and defence batteries. It is the last testimony of the destroyed marine district which lies on an area of $4,000 \mathrm{~m}^{2}$. With the help of Italian experts, restoration was launched in July 1988, and it is now open for the public as a museum. Moreover, it houses the offices of the ANAPSMH. In addition to these two monuments, a number of new facilities were introduced in the Casbah, namely 3 libraries, 2 kindergartens and 16 open-air areas. Furthermore, two main streets in the Casbah (Rue Rabah Riab and Sidi Driss Hamidouche) were rehabilitated along with the reconstruction of five public fountains (Ministry of Culture and Communication [4]).

Despite the problems of insecurity encountered during the decade 1992-2002, the Ministry of Culture and Communication succeeded in the period 1994-2000 to implement 12 restoration projects, involving 10 mosques, one castle (Dar Aziza) and the Bastion 23 (Fig. 3). In addition, refurbishment work was undertaken on the main buildings in the Basse Casbah, in an effort to recreate a link with the sea (Zadem [5]). Despite all these efforts, the trend of demolition still prevails against an active conservation and the Casbah is still being looked as a 'blight'.

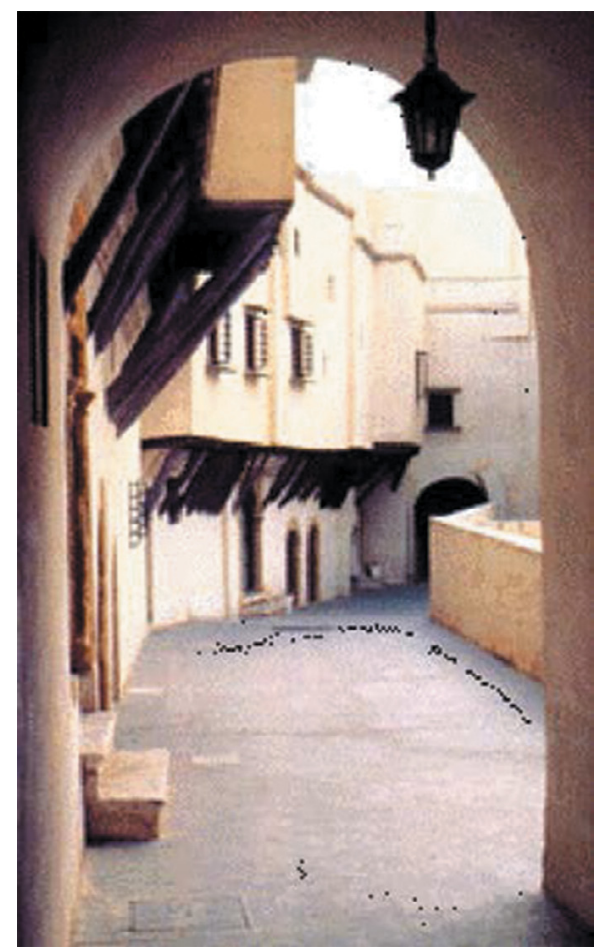

Figure 3: Few attempts to restore the Rue des Pêcheurs (Fishermen Street) at Bastion 23 (Ministry of Culture and Communication [4], p. 26). 
The present state of the Casbah is a 'large impoverished quarter' at the heart of the capital. Continued disrepair and dereliction has created a situation of desperate deterioration and squalor. With a weak planning control a 'hybrid environment' has emerged; crumbling structures have given way to high-rise apartments often constructed without any building permit, which mushroomed around old houses.

Social housing and heritage tourism are only two among several means of intervention in historic centres. One should bear in mind that services, public safety and employment are essential conditions. The provision of these demonstrates political will, which bestows renewed trust in conservation efforts and confidence in the historic centres; it sends a strong signal to the inhabitants as well as to private investors to actively participate in their safeguard.

\section{THE MEDINA OF TUNIS, TUNISIA}

The Medina of Tunis is a model of an Arab Islamic city, with its compact layout of dense low-rise courtyard dwellings distributed by alleys and narrow streets. The medina provides not only a record of the past, but also a great developing area whose future forms an integral part of the main area of the capital. With its palaces, houses, madrasas and souks, Tunis bears an exceptional testimony to the organization of space of a great Islamic city.

Inside its walls, the medina is made up of a network of streets, vaulted passages, alleys and dead-end streets. The uniform character of its urban fabric is remarkable, composed of white houses and important monuments. This urban pattern is the outcome of the urbanization process, which lasted for at least 1,000 years. The Zeytouna mosque, a major element that strives to preserve the identity of the medina, is strategically sited at the heart of the urban centre and is surrounded by several souks, lined along narrow alleyways, often covered by vaulting roofs. Thoroughfares ran between the gates and the central mosque area, and between them, extended a network of primary and secondary streets. Along the streets, district mosques, hammams and madrasas could be found.

Autonomous haras (residential areas) could be clearly distinguished from the commercial areas. It is a main characteristic of the Islamic city, where the private domain (residential) is often separated from the public domain souks (Raymond [6]). Families with different incomes lived in the same neighbourhood while occupying different-sized houses. Like other medinas in the Arab World, houses were all inward looking. The courtyard, called west eddar locally, was the heart of the house and the locus of its private family life. West eddar was protected by a succession of different spaces - the zanqa (cul-de-sac), the driba (lobby) and the skiffa - whose essential role was to delay one's entry into the house and to obstruct a direct view of the inner court.

Despite the demolition of a large number of historic buildings, the Medina of Tunis is one of the best preserved Islamic cities in the Arab world. Due to its historical and architectural significance, UNESCO inscribed the medina as a world heritage site in 1979. In the 1970s and 1980s, the Association for Safeguarding the Medina (ASM) perceived their medina as blessing and implemented one of the most outstanding conservation projects in the Arab world: rehabilitation of Hara Hafsia.

\subsection{Rehabilitation of the Hafsia quarter}

Located east of the central area of the medina, Hara Hafsia had an area of 13.5 ha on a flat site. It was bordered to the east by a boulevard built on the remains of the city walls and to the west by Achour and Ettoumi streets. Hara Hafsia was divided into three sub-neighbourhoods: 
Sidi Baian in the north, Sidi Younes in the south and a central triangular area containing both developments from the 1930s and 1960s, and the Hafsia I project area (Agence de Rehabilitation and Renovation Urbaine, [7], p. 7).

Hafsia was the Jewish quarter (Harat Lihoud) of Tunis since the 10th century. Adjacent to this hara was a military structure built by the Hafsids, from which the name Hafsia derived (McGuinness [8], p. 94). Hafsia started to deteriorate when it was abandoned by the Jews to be replaced later by poor rural migrants. During the 1920s, Hara Hafsia absorbed a large number of rural migrants, who were attracted by the cheap rent and the proximity to employment.

Since 1918 and as part of the slum clearance programme the first demolitions of insalubrious dwellings started and the area witnessed several losses. Between 1933 and 1939, the French authorities declared Hara Hafsia as an unhealthy environment and thus began to demolish numerous historic buildings. Various expropriations and clearings followed at that time, as many of the Hafsia buildings became dangerous and ruined. In 1944, Hafsia was designated an area for 'renewal' by public intervention, thus prohibiting private maintenance and repair, which further degraded the area. Due to its advanced decay and as part of the slum clearance policy, demolitions in Hafsia resumed again in 1945 (World Bank [9]). After independence, overcrowding dramatically increased, leading to Hafsia becoming an urban slum (Fig. 4). While at the beginning destruction covered 6 ha only, it was then extended to cover 13.5 ha.

Initiated by the ASM, the Hafsia project seen as a blessing aimed to stop the ongoing degradation and improve the physical and social life of the hara. While the need to reconstruct on empty lots was evident, it was a preferred approach, which would recognize the essential

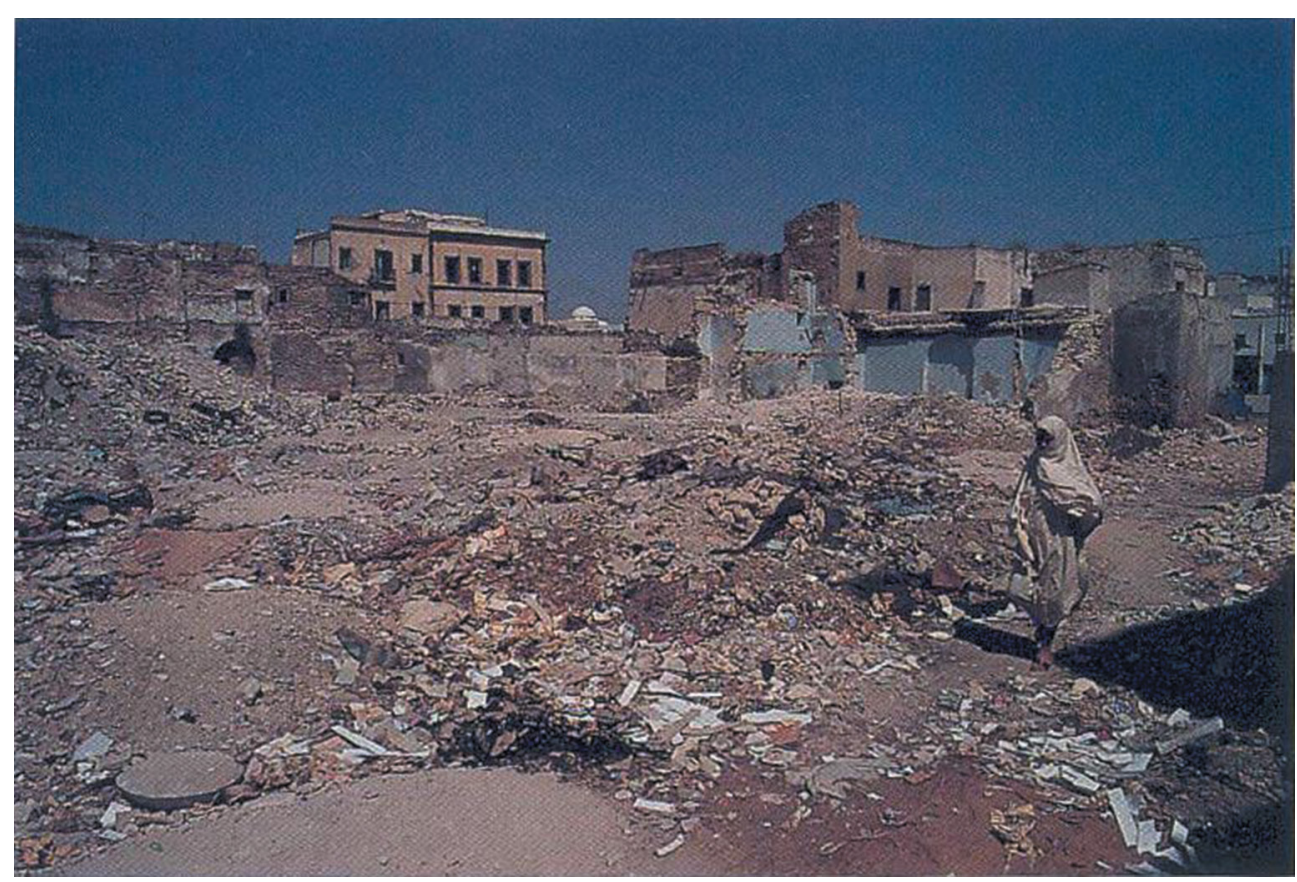

Figure 4: View of the state of deterioration and dilapidation of Hara Hafsia: looking as an urban slum before rehabilitation (Meddeb [10]). 
character of the medina with new buildings inspired by local traditional forms and patterns. In short, the project intended to apply an integrated conservation approach by involving public/private and citizen partnerships at all levels of governmental and financial institutions.

While perceiving the 'medina' as blessing, rehabilitation of Hafsia was carried out through two major schemes: Hafsia I during 1973-1977 and Hafsia II during 1981-1993 (Fig. 5). In Hafsia, the rehabilitation approach sought to improve the local inhabitants' living conditions while retaining the local trade patterns. Hafsia project worked to stop the degradation of its physical fabric, while bringing new life to the quarter. The programme included rehabilitation of monuments for tourist use, and new residential units for sale to reduce overcrowding in the central dense area. The integration of new buildings that respected the traditional character of low-rise buildings, narrow streets and walkways was another significant achievement.

The initial ambitious plans to renovate the medina by involving large-scale demolition and reconstruction were abandoned. These were replaced by projects of a more manageable scale, including proposals for rehabilitation, while enabling a gradual improvement of the area. Equally, attention shifted from a focus on single monuments to the rehabilitation of entire residential quarters. In order to implement this rehabilitation project, the following actions were selected:

- Refurbish the whole site in Hafsia by improving the infrastructure services: sewage, public lighting, water and drainage;

- Save the compact buildings while demolishing the decayed ones, as their preservation was more expensive than building new ones;



Figure 5: Rehabilitation of Hafsia I (grey) and Hafsia II (black) (Bardos [11]). 
- Rehabilitate the remaining dwellings after reducing density, meanwhile occupants will be housed in small size apartments $\left(40 \mathrm{~m}^{2}\right)$ with a toilet and kitchen;

- Maintain on site the maximum number of families forced to leave because of demolition or displacement;

- Enable a gradual augmentation of controlled rent according to families' income;

- Provide the quarter with the necessary socio-economic facilities to sustain the vitality of the area;

- Revive the traditional commercial activities and crafts; in addition to their cultural impact they can generate jobs;

- Build dwellings with a higher standard to accommodate inhabitants with medium income and who can contribute in enhancing the area;

- Re-use of the existing monuments for social and cultural activities;

- Maintain the cultural identity of the area by adapting the local traditional typology in the design of new buildings. (Yaiche [12])

Rehabilitation of Hafsia could not have been achieved without an appropriate integration of 'physical' and 'socio-cultural' revitalization. This operation resulted in the improvement of more than 200 dwelling units. Moreover, the project was seen as a blessing to the local inhabitants by creating about 2,200 jobs since the inception of Hafsia II project in 1983. While the rehabilitation work was underway, Hara Hafsia after long years of 'blight' has become 'blessing' and pride to its citizens by becoming a focal point for business, housing, commercial and tourist activities.

The considerable improvement in the quarter's image attracted more business, to the point where traffic congestion became a real problem. Property values increased and developers bought housing with the intention of creating commercial sites. Private ownership, which was initially directed at the local inhabitants in Hafsia, reached 80\% in 1995 (Bardos [11], p. 7).

The approach to conservation was comprehensive and not piecemeal, which raised people's awareness to the value of conserving their hara. After the rehabilitation of Hafsia, it has become generally desirable to live in the medina, thus bringing more people back to the area after long years of abandonment. Rehabilitation of Hafsia is generally considered one of the most successful conservation projects in the Arab world. Following this, Hafsia won the Aga Award for Islamic Architecture in 1983 and 1995.

Rehabilitation of Hara Hafsia presents a model of perceiving the past and Islamic urban heritage as 'blessing' by initiating an integrated conservation and development strategy that can be followed by other cities in the Arab world. The originality of the Hafsia project lies in the combination of two main concerns: conservation and development. The first one is social, by rehabilitating dwellings for low-income families and raising their living conditions, and the second is cultural and economic by redeveloping the built heritage for commerce and tourism (Fig. 6).

For the success of any project, there is a need to have a strong management framework like the ASM, which has been stable since its creation in 1967. The ASM has succeeded in bringing the medina back to life after decades of neglect and disrepair. Hafsia I and II rehabilitation projects represent a successful example in revitalizing the social and economic base of the medina. A number of original owners returned, making the medina once again the locus of their social and economic life. This project is a unique reversal of the negative trends and blight seen in many historic centres in the Arab world. 




Figure 6: A new life was injected in the local covered souk.

\section{OUR ISLAMIC URBAN HERITAGE: WHAT FUTURE?}

In comparison to Tunis, the Casbah of Algiers made far less progress in rescuing its Islamic built heritage. Conservation attempts came later as had the Casbah's designation as a World Heritage Site by UNESCO in 1992, 13 years later than Tunis. One of the complex problems facing the Casbah was advanced state of disrepair and dilapidation. This was mainly due to high density that reached a critical point of 4,000 persons/ha in a few districts. The situation of the Casbah with more than 70,000 people housed on the 50 ha site, often with 6-12 people in one room, made it a main source of poverty, crime and violence.

Dilapidation and lack of maintenance led the Casbah to become an 'urban slum' and 'blight' at the heart of the capital. From more than 1,200 Ottoman historic buildings in 1962 only 800 have survived, and this number is decreasing rapidly as time passes. Despite all the obstacles, a limited number of buildings have been restored. However, being scattered in the whole urban centre, they cannot have any positive impact on the whole site, where demolition by far exceeded restoration work.

Unlike Tunis, the Casbah of Algiers was not perceived as blessing that can be reused to generate income to finance its conservation work, and this was another reason for inaction. The local authorities in Algiers did not undertake the work nor gave any financial help for the inhabitants to repair and maintain their houses. The result was a desperate environment with 
dilapidated structures surrounding a few restored buildings, strengthening the status that the Casbah is blight and so should be erased in the near future.

The problem of conserving the Casbah is extremely acute. It presents a real dilemma oscillating between providing a decent shelter to the low-income inhabitants and the need for urgent urban conservation. Conserving the Casbah is not a matter of restoring few houses but a question of maintaining the vitality of reviving the entire historic centre.

The remaining urban centres should be studied as part of the present-day dynamic reality and not as a static object of contemplation and tourist attraction. Urban conservation should aim to create harmony, avoid undesirable uses and maintain the existing human scale of buildings, as well as their functional and cultural values. This means searching for new active methods to transform historic centres in the Arab World such as the Casbah of Algiers from blight to blessing, through an integrated urban regeneration strategy.

Most of the Arab historic centres have been fragmented through unwise redevelopment and slum clearance projects. However, there is still a possibility to develop measures to re-construct the unity of their dislocated urban fabric. A combination of rehabilitation, reconstruction and new infill projects, which respect the local traditional character, should be developed.

The function of urban conservation for society as a whole should primarily restore a sense of cultural identity. Just as they identify with the public areas, mosques and souks, residents must be proud of the character of their environments, and in so doing they will become their principal defenders. Privacy of residential units, human scale, physical and social integration, linkages between housing, mosques, markets and social facilities are important values that should not be neglected in any conservation action in the historic city.

Historic urban cores in the Arab world should be blessing by forming places in which people live, pursue their work and enjoy their leisure time; they are not museums. They are primarily a setting for social interaction and cultural expressions. Functional variety should be maintained, through permitting mixed uses within individual and group buildings. For example, souks and bazaars can be promoted for local trade, crafts and tourism. Declining historic areas, like the Casbah of Algiers, can be revived into attractive living heritage by reinstating a mixture of residential, commercial, administrative and tourism activities, thus transforming it from 'blight' to 'blessing'.

Change is sine qua non to revitalize the remaining cultural heritage; thus urban conservation should strive to make our Islamic urban heritage 'blessing' and not 'blight' by inserting new beating hearts in these historic centres. While change should be encouraged, it must be gradual such as in Hafsia, enabling assessment of the policy at intermediate stages, and thus permitting modification and adjustment when necessary. This means that small schemes are preferred to large-scale projects. The latter if not well prepared are most likely to fail even before starting as it happened in the Casbah of Algiers during the last 50 years.

Transforming our Islamic urban heritage from blight to blessing is about establishing a sensitive balance between socio-cultural, economic interests and environmental needs. Restoration of individual monuments without conserving or rehabilitating their historical contexts and economic forces is meaningless. It will eventually deprive the historic city of its 'inhabitants' and will end as an open air and lifeless museum. This should be avoided if there is a will to sustain a future for what survives from our Islamic urban heritage. 


\section{REFERENCES}

[1] UNESCO, Medinas: selective safeguarding of traditional habitat. The World Heritage Newsletter, 9, pp. 1-19, 1995.

[2] Lesbet, D., La Gestion de la Salubrite a la Casbah. les Annales de la Recherche Urbaine, 33, pp. 59-68, 1987.

[3] Loeckx, A., Algiers: Casbah. Encyclopedia of Vernacular Architecture of the World, Vol. 2, Cultures \& Habitat, ed. P. Oliver, Cambridge University Press: Cambridge, pp. 1599-1600, 1997.

[4] Ministry of Culture and Communication, Les Strategies de Mise en Valeur du Patrimoine, Proceedings of the Algerian-Italian colloquium, Algiers, 1992.

[5] Zadem, R., Rétrospective des Projets de Revalorisation de la Casbah d'Alger -Mise en Contexte. Proceedings of the Alger: Lumières sur la Ville Conference, 4-6 May 2002, Algiers.

[6] Raymond, A., The Great Arab Cities in the 16th-18th Centuries, An Introduction, New York University Press: New York and London, 1984.

[7] Agence de Rehabilitation and Renovation Urbaine, Troisieme Projet de Developpement Urbain; Rehabilitation du Quartier de La Hafsia, AARU: Tunis, 1985.

[8] McGuinness, J. Political Context and Professional Ideologies: French Urban Conservation Planning Transferred to the Medina of Tunis. Paper presented at the XI Congress, Association of European Schools of Planning, 28-31 May 1996.

[9] World Bank, The Rehabilitation of the Hafsia Quarter of the Medina of Tunis, Project assessment, 1994, available at www.gsd.harvard.edu/research/research-centers/cuds/ hafsia/hafsia-sumdoc.pdf (accessed 30 December 2015).

[10] Meddeb, A.B., De la Hara a La Hafsia. Architecture Mediterranean, pp. 89-98, 1997.

[11] Bardos, A., Hafsia Quarter, Medina of Tunis, Tunisia, available at www.mit.edu/akpia/ www/akpsite/4.239/hafsia/hafsia.html, 1998 (accessed 30 December 2015).

[12] Yaiche, S.A., Bilan d'une Politique d'Intervention Projets Integres et Rehabilitation Sociale. Proceedings of the Medina de Tunis, Integration de Heritage Conference, Tunis, 1992. 